\title{
Tumor suppressor genes associated with drug resistance in ovarian cancer (Review)
}

\author{
FUQIANG YIN ${ }^{1,2^{*}}$, XIA LIU $^{3 *}$, DANRONG LI ${ }^{1}$, QI WANG ${ }^{1}$, WEI ZHANG ${ }^{1}$ and LI LI $^{1,2}$ \\ ${ }^{1}$ Department of Gynecologic Oncology, Affiliated Tumor Hospital of Guangxi Medical University; \\ ${ }^{2}$ Medical Scientific Research Centre, ${ }^{3}$ Center for Translational Medicine, \\ Guangxi Medical University, Nanning, Guangxi 530021, P.R. China
}

Received December 26, 2012; Accepted March 29, 2013

DOI: $10.3892 /$ or.2013.2446

\begin{abstract}
Ovarian cancer is a fatal gynecological cancer and a major cause of cancer-related mortality worldwide. The main limitation to a successful treatment for ovarian cancer is the development of drug resistance to combined chemotherapy. Tumor suppressor genes (TSGs) are wild-type alleles of genes which play regulatory roles in diverse cellular activities, and whose loss of function contributes to the development of cancer. It has been demonstrated that TSGs contribute to drug resistance in several types of solid tumors. However, an overview of the contribution of TSGs to drug resistance in ovarian cancer has not previously been reported. In this study, 15 TSGs responding to drug resistance in ovarian cancer were reviewed to determine the relationship of TSGs with ovarian cancer drug resistance. Furthermore, gene/protein-interaction and bio-association analysis were performed to demonstrate the associations of these TSGs and to mine the potential drug resistance-related genes in ovarian cancer. We observed that the 15 TSGs had close interactions with each other, suggesting that they may contribute to drug resistance in ovarian cancer as a group. Five pathways/processes consisting of DNA damage, apoptosis, cell cycle, DNA binding and methylation may be the key ways with which TSGs participate in the regulation of drug resistance. In addition, ubiquitin $\mathrm{C}(U B C)$ and six additional TSGs including the adenomatous polyposis coli gene $(A P C)$, death associated protein kinase gene $(D A P K)$, pleiomorphic adenoma gene-like 1 (PLAGL1), retinoblastoma susceptibility gene $(R B 1)$, a gene encoding an apoptosis-associated specklike protein (PYCARD/ASC) and tumor protein 63 (TP63), which had close interactions with the 15 TSGs, are potential drug resistance-related genes in ovarian cancer.
\end{abstract}

Correspondence to: Professor Li Li, Department of Gynecologic Oncology, Affiliated Tumor Hospital of Guangxi Medical University, 71 Hedi Road, Nanning, Guangxi 530021, P.R. China E-mail: lili@gxmu.edu.cn

${ }^{*}$ Contributed equally

Key words: tumor suppressor gene, drug resistance, ovarian cancer

\section{Contents}

1. Introduction

2. Overall information on the $15 \mathrm{TSG}$ s that contribute to drug resistance in ovarian cancer

3. Gene/protein interaction network of the 15 TSGs

4. Process associations of the 15 TSGs

5. Conclusion

\section{Introduction}

Ovarian cancer is the most aggressive cancer of the female reproductive system, and a leading cause of cancer-related mortality worldwide every year. Early-stage malignancy is frequently asymptomatic and difficult to detect, and thus diagnosis usually occurs after the disease has disseminated beyond the ovaries (1). Therefore, approximately $70 \%$ of ovarian cancer cases are diagnosed at advanced stage and only $40 \%$ of women with this type of cancer survive 5 years (2). Although cisplatin-centered chemotherapy, which is the current preferred treatment modality in human ovarian cancer, significantly reduces the mortality rates and prolongs the survival time of patients, the main obstacle to a successful treatment for ovarian cancer is the development of drug resistance to combined chemotherapy (3).

Drug resistance, both intrinsic and acquired, results from a variety of factors including individual variations in patients and somatic cell genetic differences in tumors (4). Several molecular mechanisms have been implicated in the increase of resistance in cellular models of ovarian cancer. Johnson et al (5) considered that three general categories consisting of decreased cell-associated drugs, altered drug inactivation, and increased DNA damage tolerance/repair would be the platinum-based resistance mechanisms in ovarian cancer. Sorrentino et al (3) reported that increased antiapoptotic regulator activity, growth factor receptor deregulation, defective DNA damage response, and increased DNA repair activity would respond to drug resistance in ovarian cancer. It is now widely accepted that the apoptotic capacity of cancer cells is crucial in determining the response to chemotherapeutic agents (6). At the same time, apoptosis is the cellular underpinning of cisplatin-induced cell death, which associates 
with the expression of specific 'death' genes and downregulation of 'survival' counterparts (7). However, regardless of mechanisms, abnormal expression of drug resistance-related genes often plays an important role in drug resistance. Among all these drug resistance-related genes, tumor suppressor genes (TSGs) are clearly the key players.

TSGs are wild-type alleles of genes which play regulatory roles in diverse cellular activities, including cell proliferation, differentiation, migration, cell cycle checkpoint responses, protein ubiquitination and degradation, detection and repair of DNA damage, mitogenic signaling, and tumor angiogenesis $(8,9)$, and whose loss of function contributes to the development of cancer (9). It has been proved that TSGs contribute to drug resistance in several types of solid tumors. For example, TSGs including E1A, p53, Fhit, IL-24, Fusl and $B i K D D$ are associated with drug resistance in ovarian, lung and pancreatic cancer, and these genes are potential genes for gene therapy (10). In this study, on the basis of published reports, 15 TSGs which contributed to drug resistance in ovarian cancer were reviewed to provide an overview of the relationship of TSGs with ovarian cancer drug resistance; meanwhile, protein interactions and bio-association analysis were performed to demonstrate the associations of these TSGs and to mine the potential drug resistance-related genes which are closely related to the 15 TSGs.

\section{Overall information on the 15 TSGs that contribute to drug resistance in ovarian cancer}

To comprehensively collect the drug resistance-related TSGs in ovarian cancer, we first summarized a total of 39 ovarian cancer-related TSGs from the PubMed online database (http:// www.ncbi.nlm.nih.gov/pubmed/), the online Dragon database for exploration of Ovarian Cancer Genes (DDOC, October, 2012) (http://apps.sanbi.ac.za/ddoc/) (11), six candidate gene lists produced by large-scale genomic platforms on ovarian cancer from the Cancer Genome Atlas (TCGA) (12), one comprehensive expert review on ovarian cancer-related genes from Nature Reviews Cancer (13) and one bioinformatics study on ovarian cancer-related genes from PLOS One (14), followed by an advanced search with 'ovarian cancer' or 'ovarian carcinoma', 'drug resistance' or 'multi-drug resistance' or 'chemoresistance' or 'resistance' and 'name of the TSGs' performed in the PubMed database to acquire the drug resistance-related TSGs in ovarian cancer.

A total of 15 TSGs including BRCA1, BRCA2, CHEK2/ Chk2, FBXO32, MLH1, SULF1, IL24/MDA-7, p16/CDKN2A, p21/CDKN1A, p53/TP53, TP73, PDCD4, PTEN, RASSF1 and $W W O X$ which contributed to drug resistance in ovarian cancer were summarized. As shown in Table I, the modifications of the TSGs, the responding drugs, and the ways for TSGs to regulate the drug resistance in ovarian cancer were integrated. We observed that both genetic and epigenetic changes of the TSGs were contributed to drug resistance in ovarian cancer, but the latter apparently played dominant roles. As it is challenging to treat ovarian cancer through a genetic strategy, due, in part, to its heterogeneity, the reversibility of epigenetic mechanisms involved in ovarian cancer opens potential new avenues for treatment (15). The epigenomics of ovarian cancer has become a rapidly expanding field leading to intense inves- tigation, and the reversion of epigenetic changes of TSGs has already proved to be effective in reversing the drug resistance clinically in ovarian cancer. It has been reported that low-dose decitabine alters DNA methylation restoring sensitivity to carboplatin in patients with heavily pre-treated ovarian cancer, resulting in a high response rate and prolonged progression free survival, and demethylation of the MLH1 and RASSFla in tumors from day 1 to 8 is positively correlated with progression free survival $(\mathrm{P}<0.05)(16)$. These results were promising and encouraged further study on epigenetic changes of TSGs associated with drug resistance in ovarian cancer. In addition, with the exception of FBXO32 and WWOX, the other 13 TSGs participated in the regulation of drug resistance in ovarian cancer through certain pathways, in particular, through apoptosis and DNA damage-related pathways. However, regardless of pathways, the 15 TSGs responded to drug resistance in ovarian cancer through 'growth' (including cell proliferation, cell growth and cell survival) and 'death' (including cell death and cell apoptosis) (Table I).

\section{Gene/protein interaction network of the 15 TSGs}

Gene/protein function predictions based on bioinformatics analysis is a potential, feasible and valuable way for gene/ protein function mining, and numerous large-scale networks of molecular interactions within the cell have made it possible to go beyond one dimensional approaches to study gene/ protein function in the context of a network (46). GeneMANIA is a web-based database and tool for prediction of gene/ protein function on the basis of multiple networks derived from different genomic or proteomic data/sources, and it is fast enough to predict gene/protein function with significant accuracy (47). Protein-protein interactions of the 15 TSGs were analyzed using the GeneMANIA online tool. Except for IL24 and SULF1, all 15 TSGs had direct interactions (co-expression, co-localization, genetic interactions, shared pathway, physical interactions and shared protein domains) or indirect interactions (through direct interactions with an intermediate gene) with each other (Fig. 1). For example, TP53 had direct interactions with $M L H 1, B R C A 1, B R C A 2$, CHEK2, CDKN1A, CDKN2A, PTEN, TP73 and WWOX, and it had indirect interactions with FBXO32 and RASSF1; BRCA1 had direct interactions with BRCA2, MLH1, CHEK2, PTEN, $W W O X$ and $p 53 ; R A S S F 1$ had indirect interactions with BRCA1, CDKN1A, CDKN2A, CHEK2, PTEN, TP53, TP73 and $W W O X ; P D C D 4$ had indirect interactions with $B R C A 1$, BRCA2, CDKN1A, CDKN2A, FBXO32, IL24, MLH1, PTEN, TP53, TP73 and $W W O X$. These results suggested that the 15 TSGs may contribute to drug resistance as a whole.

There were an additional 6 TSGs, adenomatous polyposis coli gene $(A P C)$, death associated protein kinase gene $(D A P K) 1$, pleiomorphic adenoma gene-like 1 (PLAGL1), retinoblastoma susceptibility gene $(R B 1)$, a gene encoding an apoptosis-associated speck-like protein (PYCARD), and tumor protein 63 (TP63), which had close interactions with the 15 TSGs in the network (Table II), suggesting that these 6 TSGs may be involved in drug resistance and would be potential drug resistance-related TSGs in ovarian cancer. With the exception of PLAGL1, the other 5 TSGs have been confirmed to associate with drug resistance in several 


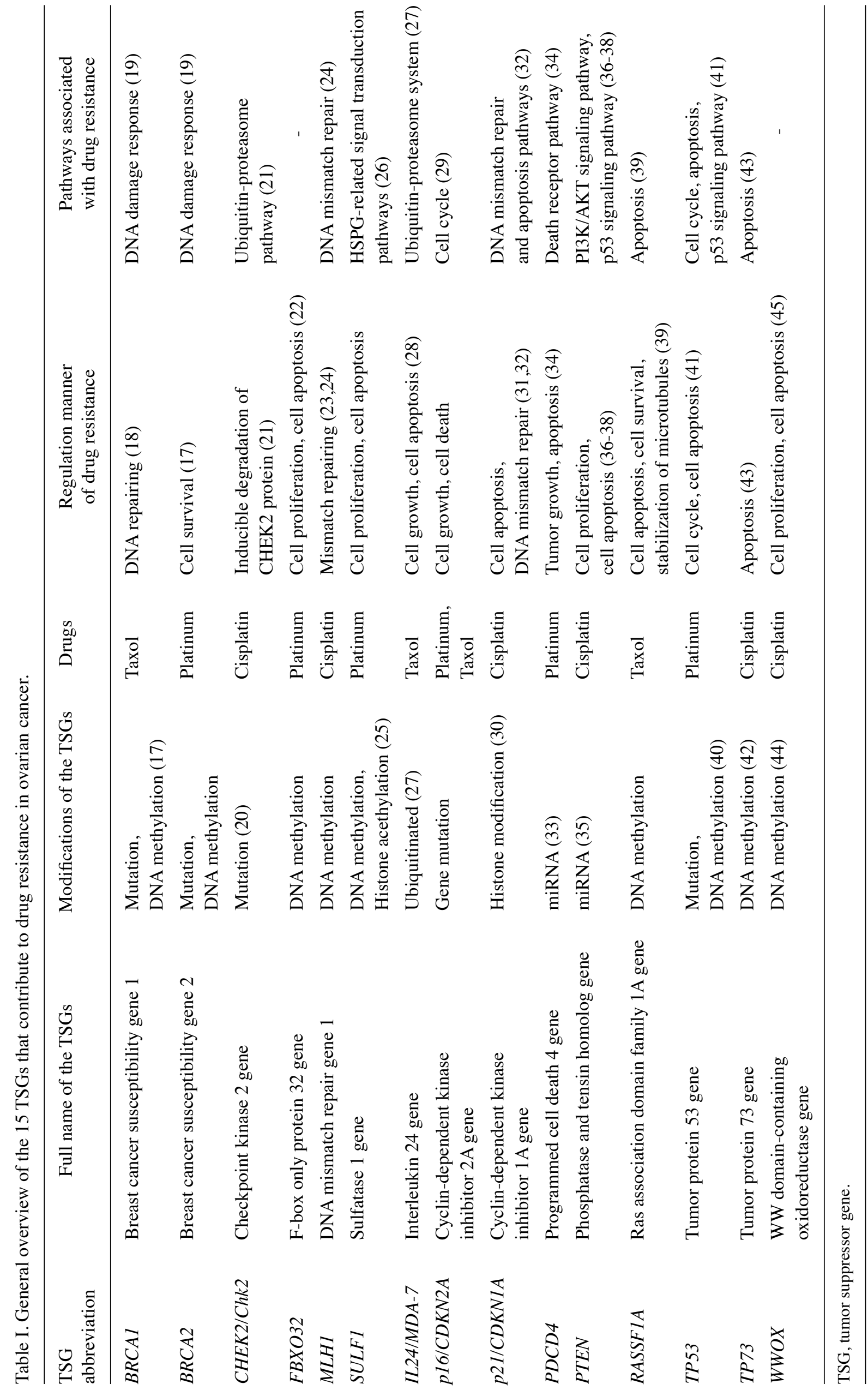


Table II. The interactions of the additional 6 TSGs with the 15 TSGs in the gene/protein interaction network.

The additional 6 TSGs in the network
Member of the 15 TSGs

(Direct interactions)
Member of the 15 TSGs

(Indirect interactions through an intermediate gene)

\section{$A P C$}

$D A P K 1$

PLAGL1

$R B 1$

PYCARD

TP63
CDKN1A, PTEN, TP53, TP73 and WWOX

FBXO32, PDCD4, PTEN, TP53 and TP73

BRCA1 and TP53

BRCA1, CDKN1A, CDKN2A, CHEK2, TP53, TP73 and WWOX
CDKN2A, CHEK2, PDCD4 and RASSF1

BRCA1, BRCA2, CDKN1A, IL24, MLH1, PDCD4, PTEN, SULF1, TP53 and TP73

CDKN1A, CDKN2A, CHEK2, FBXO32, PDCD4, PTEN and RASSF 1

RASSF 1 and PDCD4

IL24 and WWOX

BRCA1, BRCA2, CDKN1A, MLH1, PDCD4, PTEN, TP53 and TP73

TSG, tumor suppressor gene.

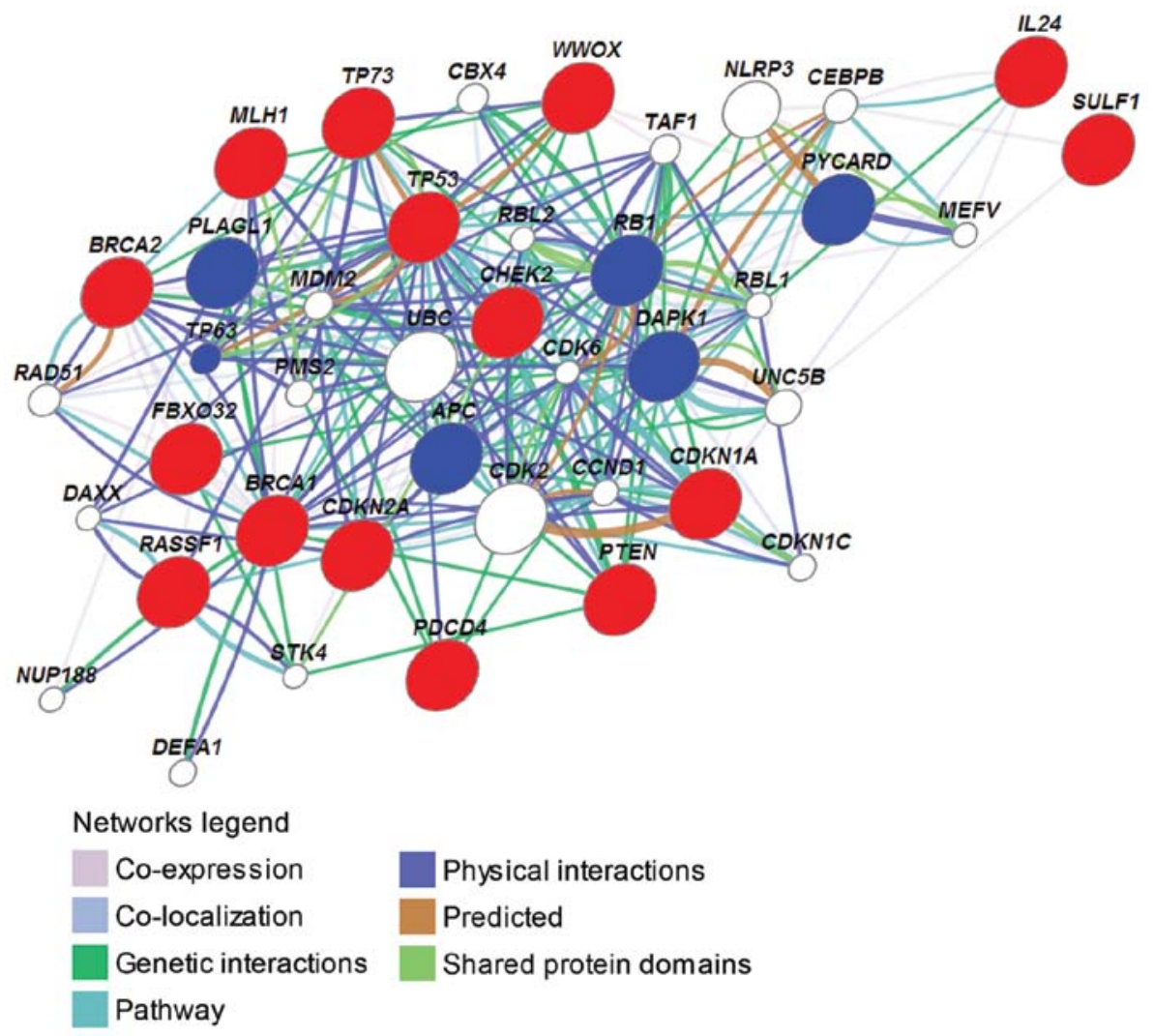

Figure 1. Gene/protein interaction network of the 15 tumor suppressor genes (TSGs) based on GeneMANIA online tool. Genes/proteins are depicted as colored circles and experimentally detected relationships between genes/proteins as connecting lines. Red circles are the 15 TSGs, blue circles are the additional 6 TSGs, and white circles are the other genes/proteins that had interactions with the 15 TSGs.

types of solid cancer. The expression status of the $A P C$ determines the relative sensitivity of colon cancer cells to histone deacetylase inhibitor-induced apoptosis which may relate to drug resistance (48); $D A P K$ is hypermethylated in drug-resistant non-small cell lung cancer cell lines and head and neck squamous cell carcinoma cell lines. Restoration of $D A P K$ into the resistant non-small cell lung cancer cells by stable transfection can re-sensitize the cells to both erlotinib and cetuximab. Conversely, siRNA-mediated knockdown of $D A P K$ induces resistance in the parental sensitive cells. These results demonstrate that $D A P K$ plays important roles in both cetuximab and erlotinib resistance (49); point mutations of the $R B 1$ encode nuclear proteins with impaired ability to induce apoptosis compared to wild-type $\mathrm{pRb}$ in vitro. Notably, three out of four tumors harboring $R B 1$ mutations display primary resistance to treatment with either 5-FU/mitomycin or doxoru- 
Table III. Annotated functions of the 15 TSGs according to the protein interaction network.

\begin{tabular}{|c|c|c|c|c|}
\hline $\begin{array}{l}\text { Annotated } \\
\text { function }\end{array}$ & $\begin{array}{l}\text { False discovery } \\
\text { rate }\end{array}$ & No. of the 15 TSGs & Other TSGs & Other genes \\
\hline $\begin{array}{l}\text { Cell cycle } \\
\text { related }\end{array}$ & $1.19 \mathrm{e}-13 \sim 9.82 \mathrm{e}-8$ & $\begin{array}{c}8 \\
(B R C A 1, B R C A 2, C D K N 1 A, C D K N 2 A, \\
P T E N, R A S S F 1, T P 53 \text { and } T P 73)\end{array}$ & $\begin{array}{l}A P C, R B 1 \\
\text { and } T P 63\end{array}$ & $\begin{array}{l}M D M 2, U B C, C D K 2, \\
C D K 6, T A F 1, C C N D 1 \\
\text { and } C D K N I C\end{array}$ \\
\hline $\begin{array}{l}\text { DNA binding } \\
\text { related }\end{array}$ & $8.91 \mathrm{e}-6 \sim 1.13 \mathrm{e}-2$ & $\begin{array}{c}8 \\
(B R C A 1, B R C A 2, C D K N 2 A, M L H 1, \\
P D C D 4, P T E N, T P 53 \text { and } T P 73)\end{array}$ & $\begin{array}{l}A P C, T P 63, R B 1 \\
\text { and } P Y C A R D\end{array}$ & $\begin{array}{l}R A D 51, P M S 2, U B C, \\
T A F 1 \text { and NLRP3 }\end{array}$ \\
\hline $\begin{array}{l}\text { DNA damage } \\
\text { related }\end{array}$ & $6.05 \mathrm{e}-11 \sim 1.84 \mathrm{e}-3$ & $\begin{array}{l}6 \\
\begin{array}{l}6 \\
(B R C A 1, C D K N 1 A, C D K N 2 A, T P 53, \\
T P 73 \text { and } C H E K 2)\end{array}\end{array}$ & TP63 & $\begin{array}{l}M D M 2, U B C, C D K 2 \\
\text { and } C C N D 1\end{array}$ \\
\hline Apoptosis & $2.45 \mathrm{e}-6 \sim 2.45 \mathrm{e}-2$ & $\begin{array}{l}6 \\
\begin{array}{l}6 \\
(B R C A 1, C D K N 1 A, C D K N 2 A, C H E K 2 \\
T P 53 \text { and } T P 73)\end{array}\end{array}$ & TP63 & \\
\hline $\begin{array}{l}\text { Signal } \\
\text { transduction } \\
\text { by TP53 }\end{array}$ & $8.71 \mathrm{e}-10 \sim 3.67 \mathrm{e}-3$ & $\begin{array}{l}\quad 5 \\
(B R C A 1, C D K N 1 A, C D K N 2 A, \\
T P 53 \text { and } T P 73)\end{array}$ & $T P 63$ & $\begin{array}{l}M D M 2, C D K 2 \\
\text { and } U B C\end{array}$ \\
\hline Aging & $2.5 \mathrm{e}-7 \sim 2.99 \mathrm{e}-2$ & $\begin{array}{l}5 \\
\begin{array}{l}5 \\
(C D K N 1 A, C D K N 2 A, C H E K 2, \\
P D C D 4 \text { and } T P 53)\end{array}\end{array}$ & & $C D K 6$ \\
\hline DNA repair & $1.43 \mathrm{e}-6 \sim 4.35 \mathrm{e}-3$ & \begin{tabular}{l}
\multicolumn{1}{c}{5} \\
$(B R C A 1, B R C A 2, C H E K 2$, \\
$M L H 1$ and $T P 73)$
\end{tabular} & & $\begin{array}{l}R A D 51, P M S 2 \\
\text { and } U B C\end{array}$ \\
\hline Cell growth & $6.34 \mathrm{e}-3 \sim 9.1 \mathrm{e}-2$ & $\begin{array}{c}3 \\
(C D K N 1 A, C D K N 2 A \text { and } T P 53)\end{array}$ & $R B 1$ & \\
\hline
\end{tabular}

TSG, tumor suppressor gene.

bicin (50); upregulated expression of PYCARD/ASC leads to enhanced sensitivity to cisplatin, gemcitabine and docetaxel in bladder cancer cells and pancreatic cancer cells $(51,52)$; TP63, with high homology with TP53, is critical for the development of stratified epithelial tissues such as epidermis, breast, and prostate (53). Expression analysis in long-term survivors reveals a significant upregulation of TP63, PTEN, GADD45a and $M A P K 1$ in metastatic gastric cancer, suggesting that these genes may be involved in drug metabolism and resistance (54).

In addition, ubiquitin $\mathrm{C}(U B C)$ had direct physical interactions with 7 of the 15 TSGs, BRCA1, BRCA2, CDKN1A, MLH1, PTEN, TP53 and TP73, and it had direct physical interactions with other genes including $M D M 2, D A P K 1$, TP63, PMS2 and DAXX; meanwhile, MDM2 (murine double minute 2 gene) had direct interactions with 7 of the 15 TSGs, i.e., CDKN2A, CHEK2, PDCD4, RASSF1, TP53, TP73 and $W W O X$, and it had direct physical interactions with other genes including $A P C, C D K 2, D A X X, R B 1, T A F 1, T P 63$ and $U B C$. Among these other genes which had interactions with $U B C$ and $M D M 2, A P C, R B 1$ and TP63 were TSGs associated with drug resistance in cancer, and death domain-associated protein (DAXX) can lead to apoptosis in cancer (55). These results indicated that $U B C$ and $M D M 2$ may play roles in drug resistance in ovarian cancer. It has previously been reported that $M D M 2$ negatively regulates tumor suppressor p53 via binding to the transactivation and the DNA-binding domains of p53 (56), and contributes to drug resistance in ovarian cancer through regulation of p53 (57). $U B C$ is low in normal kidneys but is increased in malignant tumors in vivo and in several established renal carcinoma cell lines, indicating that high expressions of the $U B C$ are important in the cancerous state of these cells (58). Similarly, $U B C$ is highly expressed in human nasopharyngeal carcinoma drug-resistant cell lines (59). However, the studies on $U B C$ associated with drug resistance are limited.

Among the annotated functions in accordance with the GeneMANIA network, eight were closely related to drug resistance (Table III). The cell cycle-related function which covered 8 of the 15 TSGs and 3 of the additional 6 TSGs was annotated with the highest false discovery rate (FDR), followed by the DNA binding-related function which also covered 8 of the 15 TSGs and 4 of the additional 6 TSGs, suggesting that these 3 pathways (functions) may be the major ways with which TSGs participate in the regulation of drug resistance in ovarian cancer. Furthermore, DNA damage and apoptosis, which both covered 6 of the 15 TSGs and TP63, may also be crucial ways for the contribution of the TSGs to the regulation of drug resistance in ovarian cancer. 
Table IV. Analysis of process associations of the 15 TSGs using PubGene bio-associations.

\begin{tabular}{|c|c|c|}
\hline Annotated process & No. of the 15 TSGs & $\begin{array}{l}\text { Article } \\
\text { (P-value) }\end{array}$ \\
\hline Methylation & $\begin{array}{c}12 \\
(B R C A 1, B R C A 2, C D K N 1 A, C D K N 2 A, C H E K 2, M L H 1, \\
\text { PDCD4, PTEN, RASSF1, TP53, TP73 and WWOX) }\end{array}$ & 0 \\
\hline Mismatch repair & $\begin{array}{c}11 \\
(B R C A 1, B R C A 2, C D K N 1 A, C D K N 2 A, C H E K 2, M L H 1, \\
P T E N, R A S S F 1, T P 53, T P 73 \text { and } W W O X)\end{array}$ & 0 \\
\hline $\begin{array}{l}\text { Cell cycle } \\
\text { checkpoint }\end{array}$ & $\begin{array}{c}11 \\
(B R C A 1, B R C A 2, C D K N 1 A, C D K N 2 A, C H E K 2, M L H 1, \\
P T E N, R A S S F 1, T P 53, T P 73 \text { and } W W O X)\end{array}$ & 0 \\
\hline $\begin{array}{l}\text { DNA replication } \\
\text { checkpoint }\end{array}$ & $(C D K N 1 A, C H E K 2$ and TP53) & 0 \\
\hline $\begin{array}{l}\text { Response to DNA } \\
\text { damage stimulus }\end{array}$ & $\begin{array}{l}10 \\
(B R C A 1, B R C A 2, C D K N 1 A, C D K N 2 A, C H E K 2, M L H 1, \\
\text { PTEN, RASSF1, TP53 and TP73) }\end{array}$ & 0 \\
\hline $\begin{array}{l}\text { DNA damage } \\
\text { checkpoint }\end{array}$ & $\begin{array}{l}9 \\
(B R C A 1, B R C A 2, C D K N 1 A, C D K N 2 A, C H E K 2, \\
M L H 1, T P 53, T P 73 \text { and } W W O X)\end{array}$ & 0 \\
\hline Cell cycle arrest & $\begin{array}{c}14 \\
(B R C A 1, B R C A 2, C D K N 1 A, C D K N 2 A, C H E K 2, F B X O 32, I L 24, M L H 1, \\
P D C D 4, P T E N, R A S S F 1, T P 53, T P 73 \text { and } W W O X)\end{array}$ & 0 \\
\hline DNA methylation & $\begin{array}{c}13 \\
(B R C A 1, B R C A 2, C D K N 1 A, C D K N 2 A, C H E K 2, M L H 1, P D C D 4, \\
P T E N, R A S S F 1, S U L F 1, T P 53, T P 73 \text { and } W W O X)\end{array}$ & $4.64 \mathrm{e}-191$ \\
\hline $\begin{array}{l}\text { G2/M transition } \\
\text { checkpoint }\end{array}$ & $\begin{array}{c}7 \\
(B R C A 1, B R C A 2, C D K N 1 A, C D K N 2 A, C H E K 2, M L H 1 \text { and TP53) }\end{array}$ & $3.22 \mathrm{e}-164$ \\
\hline Apoptosis & $\begin{array}{c}12 \\
(B R C A 1, B R C A 2, C D K N 1 A, C D K N 2 A, C H E K 2, I L 24, M L H 1, \\
\text { PDCD4, PTEN, RASSF1, TP53 and TP73) }\end{array}$ & $2.1 \mathrm{e}-119$ \\
\hline
\end{tabular}

TSG, tumor suppressor gene.

\section{Process associations of the 15 TSGs}

The process associations of the 15 TSGs were analyzed by PubGene Bio-associations (www.pubgene.org). Pubgene is a gene/protein database and web-based tool for literature mining. It carries out automated extraction of experimental and theoretical biomedical knowledge from publicly available gene and text databases to create a gene-to-gene co-citation network for 13,712 named human genes by automated analysis of titles and abstracts in over 10 million MEDLINE records (60). Therefore, gene and protein names are cross-referenced to each other and to terms that are relevant to understanding their biological function and importance in disease. Using PubGene process associations, we annotated the 15 TSGs to biological processes by probabilistic scoring, and the 10 most annotated processes of the 15 TSGs are shown in Table IV. It appears that most of the 15 TSGs played roles in processes of methylation/DNA methylation, DNA damage and repair, cell cycle and apoptosis
$(\mathrm{P}<0.001)$, suggesting that these biological processes may be the most common manner with which the 15 TSGs contribute to drug resistance in ovarian cancer.

\section{Conclusion}

TSGs play crucial roles in several aspects of cancer development including cell cycle control, signal transduction, angiogenesis, development and drug resistance, indicating that they contribute to a broad array of normal and tumor-related functions. It is proposed that TSGs provide a vast untapped resource for anticancer therapy (8). It has been reported that a total of 33 TSGs contribute to ovarian cancer development through DNA damage, DNA repair, regulating macromolecule metabolism, cell cycle, and apoptosis (14). However, an overview of the TSGs associated with drug resistance in ovarian cancer had yet to be reported. In this study, the 15 TSGs which are involved in drug resistance were comprehensively 
reviewed. Furthermore, gene/protein interaction and bio-association analysis were performed. The 15 TSGs may contribute to drug resistance as a whole in ovarian cancer, since they have close interactions with each other in accordance with the gene/ protein interaction network. An additional 6 TSGs including APC, DAPK1, PLAGL1, RB1, PYCARD and TP63, which had close interactions with the 15 TSGs (Table II) and which were associated with drug resistance in other types of solid cancer, may be potential drug resistance-related genes in ovarian cancer. $U B C$, which had direct physical interactions with a number of the 15 TSGs, may be associated with drug resistance in ovarian cancer, although its drug resistance-related functions have yet to be reported.

DNA damage and apoptosis play important roles in drug resistance in several solid tumors. DNA damage results in genetic alterations that underlie drug resistance, disabled repair and resistance to apoptosis (61). Apoptosis plays an important role in the maintenance of physiological homeostasis in response to stimuli, and failure of apoptosis would result in unopposed tissue growth and, eventually, fatal disease such as cancer (62). It has been proved that apoptosis is involved in drug resistance in several solid tumors including ovarian cancer. In this study, on the basis of gene/protein-interaction and process-association analysis, DNA damage and apoptosis were the main annotated functions/processes for the 15 TSGs, suggesting that these two biological processes may be the main manner for the participation of TSGs in drug resistance in ovarian cancer. These results are partly supported by previous studies that reported that $B R C A 1, B R C A 2, M L H 1$ and $p 21$ contributed to ovarian cancer drug resistance via DNA damage and repair, and p21, RASSF1, TP53 and TP73 contributed to ovarian cancer drug resistance via apoptosis (Table I). Furthermore, cell cycle was also a leading annotated function/process for the 15 TSGs on the basis of gene/proteininteraction and process-association analysis. It has been proved that cell cycle can create drug resistance and therefore reduce combination chemotherapeutic efficacy (63). In addition, DNA binding-related functions, which covered a total of 12 TSGs (Table III), may be another crucial process for TSGs responding to drug resistance in ovarian cancer. Methylation/ DNA methylation was also important for the 15 TSGs based on process association (Table IV); this finding was supported by previous studies revealing that 9 of the 15 TSGs were regulated by DNA methylation when they participated in the regulation of drug resistance in ovarian cancer (Table I). Collectively, five pathways/processes comprising DNA damage, apoptosis, cell cycle, DNA binding, and methylation, may be the major means by which TSGs respond to drug resistance in ovarian cancer.

\section{References}

1. Balch C, Huang TH, Brown R and Nephew KP: The epigenetics of ovarian cancer drug resistance and resensitization. Am J Obstet Gynecol 191: 1552-1572, 2004

2. Jemal A, Siegel R, Ward E, Hao Y, Xu J, Murray T and Thun MJ: Cancer statistics, 2008. CA Cancer J Clin 58: 71-96, 2008.

3. Sorrentino A, Liu CG, Addario A, Peschle C, Scambia G and Ferlini C: Role of microRNAs in drug-resistant ovarian cancer cells. Gynecol Oncol 111: 478-486, 2008.

4. Gottesman MM: Mechanisms of cancer drug resistance. Annu Rev Med 53: 615-627, 2002.

5. Johnson SW, Ozols RF and Hamilton TC: Mechanisms of drug resistance in ovarian cancer. Cancer 71 (Suppl 2): S644-S649, 1993.
6. Fraser M, Leung BM, Yan X, Dan HC, Cheng JQ and Tsang BK: p53 is a determinant of X-linked inhibitor of apoptosis protein/ Akt-mediated chemoresistance in human ovarian cancer cells. Cancer Res 63: 7081-7088, 2003

7. Cheng JQ, Jiang X, Fraser M,Li M, Dan HC, Sun M and Tsang BK: Role of X-linked inhibitor of apoptosis protein in chemoresistance in ovarian cancer: possible involvement of the phosphoinositide-3 kinase/Akt pathway. Drug Resist Updat 5: 131-146, 2002.

8. Sager R: Tumor suppressor genes: the puzzle and the promise. Science 246: 1406-1412, 1989.

9. Sherr CJ: Principles of tumor suppression. Cell 116: 235-246, 2004

10. Shanker M, Jin J, Branch CD, Miyamoto S, Grimm EA, Roth JA and Ramesh R: Tumor suppressor gene-based nanotherapy: from test tube to the clinic. J Drug Deliv 2011: 465845, 2011.

11. Kaur M, Radovanovic A, Essack M, et al: Database for exploration of functional context of genes implicated in ovarian cancer. Nucleic Acids Res 37: D820-D823, 2009.

12. Cancer Genome Atlas Research Network: Integrated genomic analyses of ovarian carcinoma. Nature 474: 609-615, 2011.

13. Bast RC Jr, Hennessy B and Mills GB: The biology of ovarian cancer: new opportunities for translation. Nat Rev Cancer 9: 415-428, 2009.

14. Zhao M, Sun J and Zhao Z: Distinct and competitive regulatory patterns of tumor suppressor genes and oncogenes in ovarian cancer. PLoS One 7: e44175, 2012.

15. Chen H, Hardy TM and Tollefsbol TO: Epigenomics of ovarian cancer and its chemoprevention. Front Genet 2: 67, 2011.

16. Matei D, Shen C, Fang F, et al: A phase II study of decitabine and carboplatin in recurrent platinum $(\mathrm{Pt})$-resistant ovarian cancer (OC). J Clin Oncol 29 (Suppl): abst 5011, 2011.

17. Yang D, Khan S, Sun Y, Hess K, Shmulevich I, Sood AK and Zhang W: Association of BRCA1 and BRCA2 mutations with survival, chemotherapy sensitivity, and gene mutator phenotype in patients with ovarian cancer. JAMA 306: 1557-1565, 2011

18. Zhou C, Smith JL and Liu J: Role of BRCA1 in cellular resistance to paclitaxel and ionizing radiation in an ovarian cancer cell line carrying a defective BRCA1. Oncogene 22: 2396-2404, 2003.

19. Borst P, Rottenberg S and Jonkers J: How do real tumors become resistant to cisplatin? Cell Cycle 7: 1353-1359, 2008.

20. Wang Y, Wiltshire T, Senft J, Reed E and Wang W: Irofulven induces replication-dependent $\mathrm{CHK} 2$ activation related to p53 status. Biochem Pharmacol 73: 469-480, 2007.

21. Zhang P, Gao W, Li H, Reed E and Chen F: Inducible degradation of checkpoint kinase 2 links to cisplatin-induced resistance in ovarian cancer cells. Biochem Biophys Res Commun 328: 567-572, 2005.

22. Chou JL, Su HY, Chen LY, et al: Promoter hypermethylation of FBXO32, a novel TGF-beta/SMAD4 target gene and tumor suppressor, is associated with poor prognosis in human ovarian cancer. Lab Invest 90: 414-425, 2010.

23. Plumb JA, Strathdee G, Sludden J, Kaye SB and Brown R: Reversal of drug resistance in human tumor xenografts by 2'-deoxy-5-azacytidine-induced demethylation of the hMLH1 gene promoter. Cancer Res 60: 6039-6044, 2000.

24. Strathdee G, MacKean MJ, Illand M and Brown R: A role for methylation of the hMLH1 promoter in loss of hMLH1 expression and drug resistance in ovarian cancer. Oncogene 18: 2335-2341, 1999.

25. Staub J, Chien J, Pan Y, et al: Epigenetic silencing of HSulf-1 in ovarian cancer: implications in chemoresistance. Oncogene 26: 4969-4978, 2007.

26. Liu P, Gou M, Yi T, et al: Efficient inhibition of an intraperitoneal xenograft model of human ovarian cancer by HSulf-1 gene delivered by biodegradable cationic heparin-polyethyleneimine nanogels. Oncol Rep 27: 363-370, 2012.

27. Gopalan B, Shanker M, Scott A, Branch CD, Chada S and Ramesh R: MDA-7/IL-24, a novel tumor suppressor/cytokine is ubiquitinated and regulated by the ubiquitin-proteasome system, and inhibition of MDA-7/IL-24 degradation enhances the antitumor activity. Cancer Gene Ther 15: 1-8, 2008.

28. Xiong J, Peng ZL and Tan X: Effects of adenoviral-mediated mda-7/IL-24 gene infection on the growth and drug-resistance of drug-resistant. Sichuan Da Xue Xue Bao Yi Xue Ban 38: 433-436, 2007 (In Chinese).

29. Kawakami Y, Hama S, Hiura M, et al: Adenovirus-mediated p16 gene transfer changes the sensitivity to taxanes and Vinca alkaloids of human ovarian cancer cells. Anticancer Res 21: 2537-2545, 2001.

30. Takai $\mathrm{N}$ and Narahara $\mathrm{H}$ : Histone deacetylase inhibitor therapy in epithelial ovarian cancer. J Oncol 2010: 458431, 2010. 
31. Xia X, Ma Q, Li X, et al: Cytoplasmic $\mathrm{p} 21$ is a potential predictor for cisplatin sensitivity in ovarian cancer. BMC Cancer 11: 399, 2011.

32. Materna V, Surowiak P, Markwitz E, Spaczynski M, DragZalesinska M,Zabel M and Lage $\mathrm{H}$ : Expression of factors involved in regulation of DNA mismatch repair-and apoptosis pathways in ovarian cancer patients. Oncol Rep 17: 505-516, 2007.

33. Cao Z, Yoon JH, Nam SW, Lee JY and Park WS: PDCD4 expression inversely correlated with miR-21 levels in gastric cancers. J Cancer Res Clin Oncol 138: 611-619, 2012.

34. Zhang X, Wang X, Song X, et al: Programmed cell death 4 enhances chemosensitivity of ovarian cancer cells by activating death receptor pathway in vitro and in vivo. Cancer Sci 101: $2163-2170,2010$

35. Yang H, Kong W, He L, et al: MicroRNA expression profiling in human ovarian cancer: miR-214 induces cell survival and cisplatin resistance by targeting PTEN. Cancer Res 68: 425-433, 2008.

36. Lee S, Choi EJ, Jin C and Kim DH: Activation of PI3K/Akt pathway by PTEN reduction and PIK3CA mRNA amplification contributes to cisplatin resistance in an ovarian cancer cell line. Gynecol Oncol 97: 26-34, 2005.

37. Wu H, Cao Y, Weng D, et al: Effect of tumor suppressor gene PTEN on the resistance to cisplatin in human ovarian cancer cell lines and related mechanisms. Cancer Lett 271: 260-271, 2008.

38. Yan X, Fraser M, Qiu Q and Tsang BK: Over-expression of PTEN sensitizes human ovarian cancer cells to cisplatin-induced apoptosis in a p53-dependent manner. Gynecol Oncol 102: 348-355, 2006

39. Kassler S, Donninger H, Birrer MJ and Clark GJ: RASSF1A and the Taxol response in ovarian cancer. Mol Biol Int 2012: 263267, 2012.

40. Chmelarova M, Krepinska E, Spacek J, Laco J, Beranek M and Palicka V: Methylation in the p53 promoter in epithelial ovarian cancer. Clin Transl Oncol 15: 160-162, 2013.

41. Reles A, Wen WH, Schmider A, et al: Correlation of p53 mutations with resistance to platinum-based chemotherapy and shortened survival in ovarian cancer. Clin Cancer Res 7 : 2984-2997, 2001

42. Zhang YL, Guo XR, Shen DH, Cheng YX, Liang XD, Chen YX and Wang Y: Expression and promotor methylation of p73 gene in ovarian epithelial tumors. Zhonghua Bing Li Xue Za Zhi 41: 33-38, 2012 (In Chinese).

43. Al-Bahlani S, Fraser M, Wong AY, Sayan BS, Bergeron R, Melino $G$ and Tsang BK: $P 73$ regulates cisplatin-induced apoptosis in ovarian cancer cells via a calcium/calpain-dependent mechanism. Oncogene 30: 4219-4230, 2011.

44. Yang W, Cui S, Ma J, Lu Q, Kong C, Liu T and Sun Z: Cigarette smoking extract causes hypermethylation and inactivation of WWOX gene in T-24 human bladder cancer cells. Neoplasma 59: 216-223, 2012

45. Liu YY, Li L, Li DR, Zhang W and Wang Q: Suppression of WWOX gene by RNA interference reverses platinum resistance acquired in SKOV3/SB cells. Zhonghua Fu Chan Ke Za Zhi 43: 854-858, 2008 (In Chinese).

46. Sharan R, Ulitsky I and Shamir R: Network-based prediction of protein function. Mol Syst Biol 3: 88, 2007.
47. Mostafavi S, Ray D, Warde-Farley D, Grouios C and Morris Q: GeneMANIA: a real-time multiple association network integration algorithm for predicting gene function. Genome Biol 9 (Suppl 1): S4, 2008.

48. Huang X and Guo B: Adenomatous polyposis coli determines sensitivity to histone deacetylase inhibitor-induced apoptosis in colon cancer cells. Cancer Res 66: 9245-9251, 2006.

49. Ogawa T, Liggett TE, Melnikov AA, et al: Methylation of deathassociated protein kinase is associated with cetuximab and erlotinib resistance. Cell Cycle 11: 1656-1663, 2012.

50. Berge EO, Knappskog S, Geisler S, et al: Identification and characterization of retinoblastoma gene mutations disturbing apoptosis in human breast cancers. Mol Cancer 9: 173, 2010.

51. Ramachandran K, Gordian E and Singal R: 5-azacytidine reverses drug resistance in bladder cancer cells. Anticancer Res 31: 3757-3766, 2011

52. Ramachandran K, Miller H, Gordian E, Rocha-Lima C and Singal R: Methylation-mediated silencing of TMS1 in pancreatic cancer and its potential contribution to chemosensitivity. Anticancer Res 30: 3919-3925, 2010.

53. Tomkova K, Tomka M and Zajac V: Contribution of p53, p63, and 73 to the developmental diseases and cancer. Neoplasma 55: 177-181, 2008.

54. Lo Nigro C, Monteverde M, Riba M, et al: Expression profiling and long lasting responses to chemotherapy in metastatic gastric cancer. Int J Oncol 37: 1219-1228, 2010.

55. Zhang X, Gu L, Li J, et al: Degradation of MDM2 by the interaction between berberine and DAXX leads to potent apoptosis in MDM2-overexpressing cancer cells. Cancer Res 70: 9895-9904, 2010.

56. Poyurovsky MV, Katz C, Laptenko O, et al: The C terminus of p53 binds the N-terminal domain of MDM2. Nat Struct Mol Biol 17: 982-989, 2010.

57. Mir R, Tortosa A, Martinez-Soler F, et al: Mdm2 antagonists induce apoptosis and synergize with cisplatin overcoming chemoresistance in TP53 wild-type ovarian cancer cells. Int J Cancer 132: 1525-1536, 2013.

58. Kanayama H, Tanaka K, Aki M, et al: Changes in expressions of proteasome and ubiquitin genes in human renal cancer cells. Cancer Res 51: 6677-6685, 1991.

59. Jiang RD, Zhang LX, Yue W, et al: Establishment of a human nasopharyngeal carcinoma drug-resistant cell line CNE2/DDP and screening of drug-resistant genes. Ai Zheng 22: 337-345, 2003 (In Chinese)

60. Jenssen TK, Laegreid A, Komorowski J and Hovig E: A literature network of human genes for high-throughput analysis of gene expression. Nat Genet 28: 21-28, 2001.

61. Casorelli I, Bossa C and Bignami M: DNA damage and repair in human cancer: molecular mechanisms and contribution to therapy-related leukemias. Int J Environ Res Public Health 9: 2636-2657, 2012

62. Li J, Feng Q, Kim JM, et al: Human ovarian cancer and cisplatin resistance: possible role of inhibitor of apoptosis proteins. Endocrinology 142: 370-380, 2001

63. Shah MA and Schwartz GK: Cell cycle-mediated drug resistance: an emerging concept in cancer therapy. Clin Cancer Res 7: 2168-2181, 2001. 